\title{
Authentic Videos in Teaching English to Engineering Students at Universities
}

\author{
Nataliia Saienko and Mariana Shevchenko \\ National Technical University of Ukraine "Igor Sikorsky Kyiv Polytechnic \\ Institute", Kyiv, Ukraine \\ https:// orcid.org/0000-0001-8898-5198 \\ https:// orcid.org/0000-0002-5881-0263
}

\begin{abstract}
The article provides the study of authentic videos effectiveness in teaching English to future engineers, focusing on listening and speaking skills advancement. Being created primarily for native speakers, authentic videos (movies, TV shows, and programs) present real-life issues and communication examples. Therefore, such records may become indispensable for engineering students, who often have limited English vocabulary. The 6-week research was conducted at the National Technical University of Ukraine "Igor Sikorsky Kyiv Polytechnic Institute" in February-March 2020. The sample was 50 fulltime 3rd-year engineering students. During the research, the participants received surveys and tests. The obtained post-experimental test results revealed that the introduction of authentic videos in the English course regularly helps improve the technical students' listening and speaking skills by almost two times. The average total mark, comprising the outcomes of listening, reading, writing, and speaking tasks, increased by 1.5 times. In the post-experimental questionnaires, the students stated that authentic videos advanced their English proficiency significantly and improved their understanding of the studied topics, including specialty-related vocabulary and issues. The vast majority of engineers-to-be expressed the desire to continue the work with videos at home. The study allows us to conclude that authentic videos are useful in English teaching since they help boost engineering students' skills, motivation, positive characteristics (concurrently amending their weak points), knowledge in the field of specialty, and increase their interest in studying English. The research results may be employed for further studies concerning English teaching with videos at university and the subsequent lifelong learning of English.
\end{abstract}

Keywords: Authentic video; Teaching; English; Engineering student; University 


\section{Introduction}

Present times require up-to-date forms of study at university, especially a technical one. Students need a unique approach to get modern education and relevant expertise that will be flexible and acceptable in the constantlydeveloping scientific field in the time of the ever-changing world. Besides, future professionals should acquire lifelong learning skills as they are among the most needed ones now for career advancement. Teaching English requires keeping up with current trends. Recently, the ongoing shift towards a mainlycommunicative approach to teaching English at non-linguistic faculties has become visible. Therefore, it is important to analyze personality types and traits of technical students and find suitable means and aids to boost their incentive to improve their skills and knowledge of English at university and after graduation.

\section{Literature Review}

There is a current trend towards adding audio-visual materials in the classroom of both humanities and technical students to boost the teaching/studying process (Malhotra \& Verma, 2020; Muslem et al., 2017). Among others, engineering students express a positive attitude to the use of videos in class (Babu H et al., 2019; Månsson, Löfgreen \& Warfvinge, 2017; Sun, 2020). During the training of future engineers, videos are mainly used for demonstration of a device, a technological process, or an issue and not for teaching English (Zabalza et al., 2020; Zhou, 2005). However, relevant authentic videos used in English lessons as educational aids can also potentially improve the levels of foreign language proficiency of the students in question and make such classes more effective. Yet, this aspect has not been sufficiently studied, making our research opportune.

Scientists from different countries across the globe are investigating the positive and negative sides of videos as a supplement to foreign language teaching. The role of video records in teaching English oral speech at university has been covered widely in scientific works. The findings are provided further. Polat and Erişti (2019) examined the impact of authentic video aids on foreign language listening skill development. According to the scholars, authentic videos demonstrate the 'real' language (spoken by native speakers of English) and give communication samples, and thus have a highly effective influence on the development of English listening skills. Also, they relieve the foreign language listening anxiety of the students who have low levels of English proficiency. Ismaili (2013) explored the beneficial nature of films for the work of students in the EFL class. The results of the investigation showed a direct connection between motion pictures and the boost of students' listening comprehension and communication skills development. Kalra (2017) described the same outcomes of the study. It was determined that films in English are motivating aids that present the speech in a close-to-authentic way, as it is done by the native speakers; thus, they significantly contribute to the enhancement of students' listening and speaking comprehension. Wang (2015) believes that authentic videos stimulate students' proactivity in English lessons and the incentive to study the foreign language, focus their attention on the educational means, and 
depict realistic circumstances and foreign cultures. In the researcher's scientific work, movies were mentioned as handy learning materials. However, it was recommended that teachers should design many varieties of classroom activities to take full advantage of videos. Hadijah (2016) expressed a similar thought about the importance of abundant techniques application in teaching English with multimedia. That means that videos should be used in diverse, compelling, and meaningful ways to be considered advantageous educational aids in the English classroom.

The employment and usefulness of authentic videos in English lessons may depend on the learners' personality traits and skills. Tordai and Holik (2018) have analyzed the engineering sector and pointed out that engineering informatics students display a low level of social skills and activity, implying that most of them are introverted and inactive. This may complicate the foreign language study at university. It has been recommended to augment the mentioned skills by oral interaction and presentations. However, no possible ways of advancing their communication and collaboration skills using videos were specified.

The foregoing literature review allows us to conclude that the subject matters of audio-visual materials use in foreign language lessons of humanities students and the communicative approach to teaching have been examined by various researchers, creating prerequisites for further study. Yet, there is a pressing need for an in-depth analysis of authentic video clips efficacy in teaching English to students of technical faculties. Among such are engineering students. In their lessons at university, videos are mainly used for specialty-related purposes, not for teaching English. However, authentic videos used in English classes may provide the opportunity to teach general and specialized English vocabulary, scientific concepts, issues, slang, and idioms that appear and are updated almost every day, being in permanent use by native speakers. The examination of the authentic videos use effectiveness for English studying (at university and after graduation) of engineers-to-be should be conducted together with the study of engineering students' characteristics, and their future employers' requirements for them.

\section{Engineering Specialists' Place in the Modern World}

Before the examination of the role and efficiency of authentic videos in English lessons of technical students, it is crucial to identify the personal characteristics of such individuals. The present article deals with engineering students since their specialty is one of the most in-demand majors at present and is regarded as a top career. Among other things, modern engineers pay special attention to the development of energy-saving technologies and the creation of environmentally-friendly devices and manufacturing processes. Due to the specified line of work, engineering skills are viewed as 'profitable' or 'valuable' worldwide now (Freitas et al., 2012, p. 2). It often triggers off 'brain drain' (highly trained or qualified individuals emigration), which is a big issue for every country. Each state wishes to retain their brilliant minds to be a worthy competitor in the field of technology and scientific innovation. Skilled migration 
of engineers may provoke deterioration or even collapse of specific technology sectors of a country. Consequently, a decline in the country's scientific value, socio-economic development, as well as economic and financial losses may happen. The outflow of engineers can occur for various reasons: low wages, underestimation by management, search for better prospects, superior training and working conditions, etc.

At present, the issue of education and preventing the migration of specialists in industries that are rapidly gaining value in the international arena, such as environmental engineering, is urgent. Such specialists are engaged in preserving the environment and developing new technologies to improve people's lives and even save them. Now, almost every country has a plan for the development and large-scale implementation of 'green' technologies, based on renewable sources (solar-, wind-, wave energy, biomass, etc.). It is done by engineers in various fields. Therefore, it is essential to update the university education of engineering students that are non-native speakers of English per the needs of today, showing the real possibilities of applying the acquired knowledge, including English. Often engineering students view it as the possible way to immigrate to other countries that offer them more career prospects. However, teaching English with modern means can help them find many opportunities without a radical change in their lives. It can help gain new expertise, knowledge, and practice even in the students' homeland, opening the world to them from a different perspective, including the world of science. Moreover, adequately studied English - utilizing modern audio-visual materials currently available in abundance - helps engineers-to-be gain access to the global scientific community of innovators without effort, promoting mobility, i.e., the 'circulation' of specialists within a global labor market (Freitas et al., 2012), and lifelong learning of English.

\section{Relation between Engineering Students' Characteristics and Authentic Videos Effectiveness in English Lessons}

The new tendencies have a significant impact on student-engineers' personalities and cognitive characteristics. Among them, researchers (Kline \& Lapham, 1992; Tordai \& Holik, 2018; Van Der Molen et al., 2007) uniformly determine such most distinctive ones as capability of independent (autonomy) and dependent work, emotional stability (anxiety control), tough-mindedness, conscientiousness (i.e., showing accuracy and precision in activities), responsibility and reliability, moderate cooperation, as well as a low level of such social skills as effective communication and self-expression.

Engineering students, who have work experience, have defined skills vital for their future profession. The highest ratings have problem-solving, causal relationships understanding, ability to apply knowledge, work precision, adaptation to change, goal orientation, and flexibility (Tordai \& Holik, 2018, pp. 35-37). Graduates emphasized that communication skills, problem-solving, and interpersonal skills (cooperation) are among the most valued generic competencies for employability (Markes, 2006, p. 18; Tordai \& Holik, 2018, p.37). The students viewed this expertise as more critical in the engineering 
profession than hard skills. At the same time, the vast majority of respondents said that usually the least important skill for their success in the professional field is written communication.

\section{Skills and Competencies of Engineering Students to Be Advanced}

There is no doubt that students' abilities, opinions, and needs are essential for differentiated English teaching at university. However, that is the employers who dictate what is needed in engineering branches at the moment. Thus, they indirectly determine the competencies and skills to be promoted in the course of English teaching. The following are skills and competencies of engineering students that can be developed and advanced simultaneously with four basic language skills in the course of English teaching with authentic videos at university.

A thorough analysis revealed that employers in the various branches of engineering usually require their employees to comply with standards and have the following competencies (Eldeen et al., 2018, p. 965; Yusoff et al., 2012): interpersonal skills; intra-personal skills; basic (computer) skills; specific (professional) knowledge.

Considering the ranking of the employability skills currently required by worldwide engineering industries, university lecturers of English can prioritize the student skills that should be improved in the course of the foreign language study, as well as choose the most suitable means of teaching.

Understanding and being able to speak English and other languages are among the top benchmarks of a modern specialist in any technical field. That defines the vital role of English for engineers. The key criteria that employers in engineering branches utilize for worldwide staff selection were gathered (Yusoff et al., 2012, pp. 498-499), categorized, and are provided further. It is possible to develop and advance the majority of them with the introduction of authentic videos in English language lessons of engineering students on an ongoing basis: communication skills; teamwork; knowledge of contemporary issues; professionalism; problem-solving and decision-making skills; competency (making use of modern engineering devices and software, continuous acquisition of in-depth technical competence in a particular engineering branch); lifelong learning (recognition of the importance of engagement in lifelong learning, and setting personal goals).

The investigation results determine the course of English language teaching at a technical university. It is clear that to train successful and versatile engineering specialists, it is essential to incorporate the development of non-technical competencies and soft skills across curricula (Itani \& Srour, 2016; Riemer, 2003) and motivate students for lifelong learning, using modern aids. Non-technical competencies and soft skills are the interpersonal attributes you need to succeed in the workplace: communication abilities (listening, presentation, public speaking, storytelling, persuasion, verbal communication, reading body language), critical thinking (creativity, flexibility, curiosity, logical thinking, 
problem-solving, research, innovation), leadership (giving clear feedback, delegation, decision-making), positive attitude (cooperation, confidence, patience), and teamwork.

\section{Lifelong Learning of Engineering Students}

It is important to remember that an individual's learning usually happens not solely in a formal ambience (university classroom). It occurs at every moment of their life, including non-formal (professional associations) and informal (library, museum, cinema, family, etc.) settings. As regards lifelong learning, it is a continuous process, among key features of which are diversity, flexibility, and availability at any time and place. Learning opportunities can be found everywhere. The mentioned kind of learning emboldens people to acquire all the knowledge and skills they may require throughout their lives (both personal and professional) and apply them with creativity, assurance, and satisfaction in any circumstances and environments (Djebbari \& Djebbari, 2018, p. 9). In the process of continuous learning, people should regularly update their competencies, not allowing their knowledge and skills to become obsolete. For instance, via utilizing mobile-assisted technologies that can be integrated into an English course at university and used by students anywhere off-campus. Technologies were proven to be a powerful tool to develop self-directed learning skills when adequately used (Saienko \& Lavrysh, 2020).

To be considered a successful lifelong learner, a person must possess the following traits (Djebbari \& Djebbari, 2018, p. 10): be interdependent and independent (autonomous), logical and analytical, methodical and disciplined, curious, motivated to learn and grow, responsible for their learning and its evaluation, able to think critically and respond to various situations, as well as willing to collaborate with others. Well-developed communication skills, higherorder thinking skills, and information-seeking and retrieval skills are also vital. That makes lifelong learning perfect for engineering students, taking into account their characteristics mentioned in the article earlier.

Turning English language classrooms into ones with lifelong learning objectives may emphasize technical students' English language proficiency, expand their experiences through attaching state-of-the-art technology; boost creativity, initiative, responsiveness, adaptability, innovation, and ability to change. Thus, to prepare engineering specialists with high skills in English, the lecturers need to not only provide the students with theoretical and practical knowledge of the foreign language but also arouse their interest in the studied subject. Besides, English lecturers should inspire technical students for continuous learning: at first - off-campus, and after graduation - as lifelong learning. That can be done only via the employment of modern studying aids and demonstration of their efficiency and usage variety.

\section{Authentic Videos in English Lessons of Engineering Students}

To encourage engineering students to be proactive while doing activities aimed to develop or improve the aforementioned soft skills, it is better to use authentic videos most diversely. Such videos promote active study in English lessons and represent one of the main elements of student-centered learning environments. 
That is because such a type of teaching usually allows students to get authentic tasks and gain relevant learning experiences (Elen et al., 2007, p. 105).

By the word 'authentic,' a non-educational character of any tool is meant. Authentic aids are created, in the first place, for native speakers primarily by individuals speaking a language as their mother tongue. Verbal, audio-visual, and written elements (e.g., subtitles) of authentic videos reflect the real-life communication examples (Polat \& Erişti, 2019, p. 137). That is the reason why the rate of speech and vocabulary heard on them are never artificially reduced to be more comprehensible (Shahani et al., 2014, p. 44), unlike on the records created purposefully for language teaching (for non-native speakers). The examples of such materials are present in abundance in any format everywhere now - movies (and their fragments), TV shows, programs, etc. on the Internet platforms (YouTube, Netflix, Hulu, Amazon Prime), DVD/Blu-Ray disks, in the form of digital releases. Foreign language lecturers often discard authentic videos in English. It happens since they subjectively regard such records as too time-consuming and difficult-to-understand for their technical students, who presumably have a limited volume of general English. The mentioned foreign language vocabulary may be limited in terms of shortenings (e.g., such as 'ad' for advertisement, 'vid' for video), slang, idioms, and, especially, abbreviations and acronyms used by English-speaking countries in written and oral communication sometimes even more often than their full forms (e.g., ASAP - as soon as possible, CEO - Chief Executive Officer). However, they are just as needed as the standard dictionary. If they are commonly used by native speakers of English, they are most definitely utilized in the workplaces, and so, by the potential foreign colleagues of the now-students.

To meet the requirements of the employers while simultaneously taking into account the personality characteristics of engineering students, an English language lecturer needs to set three aims of teaching with authentic videos (Wang, 2015, pp. 23-24). Firstly, it is necessary to facilitate the development of the students' language skills (primarily, listening and speaking). It is a fact that students get tired much quicker of strictly listening than when the audio is accompanied by some visual. Videos can enhance their attention focus on the audio material, providing much more information through the visual and auditory receptors concurrently. Besides, authentic video aids can create a more realistic language learning environment and stimulate students' interest in English studying and improvement of their comprehensive linguistic competence. Since the development of technical students' language abilities is generally connected with their incentive and interest in what they are studying, it is motivation, namely instrumental and integrative, that plays a vital role in the foreign language training of future engineers (Saienko, 2017). It is confirmed by the cognitive theory of motivation, according to which our expectations guide our behaviors, usually, in ways that would lead to desirable outcomes. Secondly, the cultivation of the students' intercultural communication competence is essential. When an authentic video is shown in the classroom, it does not only present information about the language but also demonstrates the culture of English native speakers and ultimately serves as a support for 
students' communicative competence in English. And finally, videos in question have to develop students' aesthetic values and ability to appreciate English artistic videos (including movie fragments) in their foreign language lessons. Technical students should understand that the not-inherently-technical character of a film or show does not downplay its significance and does not mean pure entertainment in the class. Authentic videos exist in multiple genres, and various engineering subject matters can be found frequently in virtually any of them, even in Hollywood movies. Clips selected correctly (meaning those that depict an aspect of the students' field of specialization - an issue, a process, a device, etc.) can expedite engineering students' deep thinking, critical review, and technical discussions.

Of all the mentioned characteristics of engineering students and the requirements of employers in their professional sphere, the main emphasis in the majority of examined scientific works (Shevchenko, 2015a; Reddy, 2019; Riemer, 2003; Van Der Molen et al., 2007) is on the importance of paying more attention to the development and enhancement of communication abilities (interpersonal skills) of students. The reason for that is that engineers, being typical realistic individuals, prefer to work with things rather than ideas or people and enjoy physical labor more than mental activities, and so, have a lower level of social skills than humanities students. It highlights the significance of technical students' English oral speech advancement at university.

Communication skills improvement can be put into action through problembased learning, case study, student presentations, and projects on the subject matters of lessons structured around video clips that are thematically-relevant to students' field of specialization. Discussions of compelling and relevant engineering issues seen on video records help to boost students' oral interaction using general English vocabulary and specialized terminology. At the same time, reflection on the lesson's topic promotes students' critical thinking and, ultimately, advances their proficiency in interaction with a degree of fluency and spontaneity. It is recommended to organize it in the form of cooperative learning (teamwork and collaboration) to stimulate proactive rather than reactive English study with feedback and encourage active participation in the foreign language learning process. It creates the basis of the student-centered approach to education, which, in turn, motivates technical students and prepares them for the employment challenges of today.

Authentic videos in English are multifunctional. They can serve the English teaching process at university in various ways: to improve engineering students' listening and speaking skills (vocabulary practice), information recall, prediction, writing, knowledge of speech structure and grammar, teamwork, and even English pronunciation. In the auditorium, authentic video clips stimulate discussion (of a wide range of depicted issues/situations/subjects) with the justification of one's viewpoint, argument provision and persuasion, critical thinking, as well as problem-solving. Moreover, the videos under consideration may also serve as the basis for such subsequent independent work 
of students as preparation of presentations and clear and logical speeches on the lesson's topic or a related one. Assignments based around video records introduce interest and incentive boost in the English language lessons, showing the authenticity of specialty-relevant topics/issues, learning material, and the studied foreign language vocabulary. The information above demonstrates the productivity of video records for the introduction of the communicative approach to teaching English: they create the conditions for focusing on communication in class via showing a real conversation process and promoting learning-by-doing after the viewing; provide rich and meaningful input in the form of authentic language discourse, and stimulate collaborative learning (Shevchenko, 2015a).

The role of authentic videos in teaching English at technical universities has been examined previously (Shevchenko, 2015b). The current article's topic is its logical continuation, studying the effectiveness of the use of authentic videos in teaching English to a specific group of technical students - future engineers. The research is done via exploring the characteristics of engineering students, the requirements for them from employers, and the features of authentic videos utilization in English lessons at universities to achieve positive results. However, the matter would not be thorough enough without an experimental verification of the obtained results.

\section{Aim of the Study}

This article aims to study and experimentally verify the effectiveness of using authentic videos in teaching English to engineering students at universities.

\section{Hypothesis}

We hypothesize that introduction of authentic videos in the English course regularly will improve engineering students' listening and speaking skills.

\section{Materials and Methods}

\section{Research Design}

The study employs a mixed-methods research approach. The quantitative research method relied on collecting and processing data through the use of preand post-experimental questionnaires and tests (B2 level). The qualitative research method focused on interpreting the information. The theoretical data collected and presented in the current work were experimentally verified. The results are provided further in the article.

\section{Participants and Procedure}

For the 6-week experiment in February-March 2020, two groups of 3rd-year engineering students of the Institute of Energy Saving and Energy Management (IEE) of the National Technical University of Ukraine "Igor Sikorsky Kyiv Polytechnic Institute" were selected. Each group had 25 full-time students with an equal number of male and female persons. The level of proficiency of the majority of the students chosen for the experiment was B2 (Upper-Intermediate). Group 1 was experimental, and therefore was studying with authentic videos as educational aids. In its turn, Group 2 (a control one) was utilizing mainly 
conventional printed materials - on the same topics as Group 1 - and only several times they listened to audio recordings when it was needed for the coursebook exercise doing. Each group was provided with various tasks to check their comprehension throughout the experimental study.

Before and after the experiment, the engineering students received links to Google Forms with two questionnaires prepared by us, both with open-ended and closed-ended questions. Group 1 and Group 2 also received two printed tests (pre- and post-experimental) - each was the same for both groups. The preexperimental test was prepared by us, taking into account the terminology the students had come across in their coursebook ('Cambridge English for Engineering' by Mark Ibbotson). In the post-experimental test, we used the information and vocabulary studied during the experiment and the lexis from the coursebook. The tests contained various tasks for students with B2 level. Our identification of the students' English competence was conducted per Cambridge B2 First (FCE) exam format. That is, our pre- and post-experimental check of the students' knowledge of English consisted of Listening, Reading and Use of English, Writing, and Speaking (interviewing).

The groups' pre-experimental surveys were identical, whereas the postexperimental ones were different for each group, aiming to clarify students' opinions about their learning experience during the experiment. The preexperimental questionnaire (Appendix 1) aimed to get the students' views on different aspects of their English lessons and thoughts concerning the level of their skills development at that moment. After the survey, both groups passed a pre-experimental test to check their listening and reading comprehension, as well as writing skills. Following the test, students' speaking skills were analyzed during an interview on the subject of their specialty, corresponding to the description of B2 level by Common European Framework of Reference for Languages (CEFR). Listening comprehension in the tests was checked using short podcasts available in free access on the Internet, for instance, on the British Council website.

Preliminary test results showed an approximately equal level of English knowledge of both groups. Engineering students of Group 1 (experimental) were studying with the use of authentic videos in English and performed tasks based on the information from them to check listening and reading comprehension, as well as the use of English, grammar, speaking, and writing. Each activity was a logical continuation of the previous one, differing in difficulty level and varying in the form of fulfillment (individual-, pair-, team-, the-whole-group work). That was done to develop and improve as many skills as possible while corresponding to engineering students' characteristics and levels of English proficiency. The selected authentic video aids were fragments of feature films (clips from top-rated Hollywood movies thematically relevant to their specialty) and short scientific programs related to the lessons' topics: ecological catastrophes, energy conservation, and modern technologies. As the research results provided in the current article imply, engineering students' social skills are usually the least developed ones. Therefore, during the 
experiment, special attention was paid to the advancement of oral communication skills, i.e., listening and speaking.

After the experiment, the procedure was the same. A separate post-experimental questionnaire for each group (Appendix 2; Appendix 3) had been prepared on Google Forms to ask the students about their study during the experiment. Besides, there was a post-experimental printed test followed by oral interaction (an interview) with the lecturer to check whether the engineering students' common and specialized knowledge, as well as listening-, reading, writing, and speaking skills had improved.

\section{Data Collection and Data Analysis Tools}

All the pre- and post-experimental questionnaires and tests were prepared by us and are protected by copyright. The analysis of the data contained two stages. The students' results of pre- and post-experimental tests were checked, analyzed, and summarized by us in the form of a comparison table of tests results provided further in the article. The surveys of students were conducted with the help of Google Forms service, and the answers were automatically systematized, analyzed, and graphically presented. The questionnaires comprised both closed-ended and open-ended questions.

\section{Ethical Issues}

The students were informed about the aim and procedure of the experiment and gave their agreement for the participation and academic achievement processing. Students could refuse to participate at any stage of the experiment without any academic consequences. The procedure of the research had been approved by the Scientific Council of the Faculty of Linguistics, Igor Sikorsky Kyiv Polytechnic Institute. The experts ensured that the investigation was performed in proper conditions and confirmed the reliability of the obtained results.

\section{Research Results}

After six weeks, a post-experimental B2 level test (the same for both groups) was conducted. The purpose was to check students' recall of the studied topics, listening and vocabulary comprehension, and ability to put it in use (speaking and writing tasks). Most attention was paid to testing students' listening and speaking skills to confirm or refute our hypothesis about the effectiveness of authentic videos introduction in the English course regularly for improvement of engineering students' listening and speaking skills. A comparison of the preand post-experimental tests results is presented in Table 1.

Table 1: Comparison of pre- and post-experimental tests results

\begin{tabular}{|c|c|c|c|c|c|c|c|c|c|c|}
\hline & \multicolumn{2}{|c|}{ Listening } & \multicolumn{2}{|c|}{ Reading } & \multicolumn{2}{|c|}{ Writing } & \multicolumn{2}{|c|}{ Speaking } & \multirow{2}{*}{\multicolumn{2}{|c|}{ Total }} \\
\hline & \multicolumn{8}{|c|}{ average mark ratio per activity } & & \\
\hline & \multicolumn{2}{|c|}{$\max .3$} & \multicolumn{2}{|c|}{$\max .2$} & \multicolumn{2}{|c|}{$\max .2$} & \multicolumn{2}{|c|}{$\max .3$} & \multicolumn{2}{|c|}{$\max .10$} \\
\hline & G1 & G2 & G1 & G2 & G1 & G2 & G1 & G2 & G1 & $\mathrm{G} 2$ \\
\hline Pre-exp. test & 1.32 & 1.16 & 1.56 & 1.64 & 1.28 & 1.24 & 1.4 & 1.28 & 5.56 & 5.32 \\
\hline Post-exp. test & 2.48 & 1.2 & 1.8 & 1.8 & 1.52 & 1.28 & 2.4 & 1.32 & 8.20 & 5.60 \\
\hline
\end{tabular}


The positive change of Group 1's (G1) results was noticeable: the average total mark during the pre-experimental test was 5.56 out of 10 and became 8.20 after the experiment. The average listening and speaking ratios increased the most, by 1.9 and 1.7, confirming the benefits of using authentic videos to advance these skills of engineering students. Reading and writing skills ratios of G1 increased concurrently - by 1.15 and 1.19, respectively. Group 2's (G2) outcomes did not show significant changes: 5.32 (pre-experimental total average mark ratio) and 5.60 (post-experimental one). Among G2's skills, only the improvement of reading comprehension was apparent - by 1.1, whereas the other three (listening, writing, and speaking) demonstrated growth within the range of $1.031-1.034$.

Before and after the experiment, all students (G1 and G2) were asked to fill out the questionnaires (Appendix 1; Appendix 2; Appendix 3). They had been prepared by us and posted on Google Forms, comprising both closed-ended and open-ended questions. It was done to discover their opinions concerning different aspects of work in English lessons. They displayed contrasting answers. Both groups expressed their neutral satisfaction with the amount and diversity of tasks aimed to improve their communication skills before the experiment. The level of motivation to do some further English study offcampus was average (50\%-60\%). However, after the experimental study with authentic videos and various assignments for boosting their social (oral interaction) skills, as well as language-in-use practice, Group 1 voiced other opinions. Qualitative data have shown that $88 \%$ of G1 students expressed the desire to continue the work with videos at home. $90 \%$ stated that exercises with authentic videos used as teaching aids had improved their understanding of the studied topics, including specialty-related vocabulary and issues. Furthermore, $94 \%$ believed that assignments with content prediction, role-plays, and argumentation-based discussions using the lesson's lexis had advanced their English proficiency significantly. Yet, the control group's responses did not show a similarly high percentage of satisfaction. According to them, their incentive to continue English study at home was $64 \%$, the ease of comprehension averaged $70 \%$, and the ease of speaking tasks fulfillment amounted to $60 \%$.

The results of the research and experimental verification demonstrate the considerable influence of authentic video records on various aspects of English teaching. The similarity of the positive outcomes of researchers from different countries confirms the productive nature of authentic video records. In a short time, they have proved to be efficient for the advancement of engineering students' competencies and skills, being just the right aids for their personal qualities (characteristics) and to their liking. Thus, the current study has the potential for further examination of authentic videos' long-term effectiveness in teaching engineering students English at university and their role in the students' lifelong learning of English. 


\section{Discussion and Recommendations}

Engineering students usually have such qualities as capability of independent and dependent work, emotional stability and tough-mindedness, conscientiousness, responsibility and reliability, moderate cooperation, a low level of such social skills as effective communication and self-expression. The students majoring in engineering (with work experience) and graduates regard oral interaction skills, problem-solving, ability to apply knowledge, and interpersonal skills as the most valued generic competencies for employability in their professional sphere, while written communication skills are believed to be the least significant (Kline \& Lapham, 1992; Tordai \& Holik, 2018; Van Der Molen et al., 2007). These fully correspond to the key criteria that employers in engineering branches utilize for comprehensive staff selection: communication skills (native and foreign languages), teamwork, knowledge of contemporary issues (current events and technologies), professionalism, problem-solving and decision-making skills, critical thinking, competency (general and in a specific engineering field), motivation, lifelong learning. It is to the improvement of them the most attention should be paid in English lessons with authentic audiovisual materials.

Authentic videos are records created primarily by individuals speaking a language as their mother tongue, in the first place, for native speakers of some language, not for educational purposes. On such videos, verbal, audio-visual, and written elements reflecting the real-life communication examples are presented, so their speech rate and vocabulary are never specially reduced to be more understandable for non-native speakers. The most popular among authentic videos are feature films (and movie clips), TV shows, and programs, which are available on the Internet platforms, DVD/Blu-Ray disks, and in the form of digital releases. An English language lecturer's aims of teaching with authentic videos are the facilitation of the students' language skills development (primarily, listening and speaking); cultivation of students' intercultural communication competence; development of students' aesthetic values and the ability to appreciate authentic videos in English lessons along with the understanding that the not-inherently-technical nature of a movie or show does not downplay its significance in class since engineering issues can be found in them frequently.

The advancement of communication skills (oral speech) of engineering students is believed to be paramount. Such skills can be improved through problembased learning, a project method, discussions of compelling and relevant engineering issues seen on authentic videos, reflection on the lesson's topic (promotion of critical thinking); student presentations, and projects on the subject matters of lessons, using general English vocabulary and specialized terminology (Saienko, 2017; Shevchenko, 2015b). We recommend organizing the work in class in the form of cooperative learning (teamwork) to stimulate proactive English study.

The use of authentic videos in English lessons should advance approximately $90 \%-95 \%$ of the competencies and skills of students, prioritized by employers in 
the engineering sphere around the globe. Simultaneously, they should boost the positive characteristics of engineers-to-be and amend their weak points.

The experimental verification of the article's topic confirmed the effectiveness of authentic videos in English lessons of engineering students. The study of the experimental group was organized with the use of authentic videos, taking into account the characteristics of engineering students (skills and personal traits). The results of the post-experimental test demonstrated the noticeable rise of the experimental group's recall of the studied topics, listening and vocabulary comprehension, and ability to put it in use in oral and written form, which is in line with other studies (Ismaili, 2013; Kalra, 2017; Polat \& Erişti, 2019). Simultaneously, the outcomes of the control group, who studied without videos, remained practically unchanged.

Also, the majority of the experimental group's engineering students mentioned the significant increase of satisfaction with their English proficiency advancement, improvement of their understanding of the studied topics with terminology and issues relevant to the specialty, and expressed the desire to continue the work with videos at home, as well. The opinions of the control group were far from equally unanimously high.

These results are supported by other studies. For example, Ismaili (2013), after the experimental verification of the effectiveness of using movies in the EFL classroom, revealed the improvement of students' listening comprehension and speaking ability, increased English vocabulary, as well as learning interests and motivation through demonstration of real-life situations and conversations. The findings of Ardiansyah (2018) also proved the positive influence of authentic videos implementation on the students' listening skills. According to the researcher, such audio-visual aids may bring the content and the studied subject matter to life for students, enabling them to make important connections in the world beyond the classroom.

Based on our experience of using authentic videos in the English classroom, we recommend some practical ways to boost engineering students' collaboration and oral speech using authentic video clips in English. They may be taken from feature films but are always thematically relevant to the students' specialty.

- Translation and Putting in Order (this activity draws on students' linguistic repertoires - translanguaging; the task's goal is to enrich engineering students' vocabulary and knowledge of English dialogue structure and develop logical thinking). Each group of students receives from their lecturer a set of papers. On each, a sentence is written in their native language. These are the dialogue lines from the authentic (English) video, which the lecturer has translated into the learners' language. The students should translate them back into English and quickly put in the right order. After that, everybody watches the record in English and checks if their translation and the order of the lines were correct.

- Dialogue Guessing (this activity aims to develop students' prediction, writing- and speaking skills, as well as provide the opportunity to practice 
English in use). Students watch a muted fragment with actively changing events or facial expressions/body language on screen. They need to write down possible dialogues of the characters, utilizing the handouts with the word-list in English they have received from their teacher. Afterward, they can read their dialogues synchronously with the video (still played without sound). Then, the video is replayed once more unmuted, and everyone checks whether they were right.

- Sequence of Events (the assignment improves engineering students' prediction and oral communication skills, and expands their general and technical English vocabulary). Students work in pairs. They get cards on which the events from the video are written in English. The pair reads them and consults with their foreign language lecturer if there is a problem with the understanding of some words or collocations. Then, one of the pair sits their back to the screen, on which the video will be played, and the other one sits facing the screen. After the record has been set going (without sound) by the teacher, the latter student tries to explain what they see, and the former looks for the suitable card with an event and puts one card after the other to form the logical succession in the end. When all is done, the lecturer plays the clip with sound, and students check their accuracy.

- Recall and Putting in Order (the exercise is useful for training technical students' recall ability). The work can be done with the whole group, teams, or pairs. Having watched an authentic video (a movie fragment) in English, students receive a set of event cards which they should arrange in order. When the whole group is doing the task, one student reads their card aloud, and someone in the class reads theirs if they think that their card is a logical continuation. In pairs and teams, the work is the same but with the possibility of time limitation.

- Shadow Reading (the task is beneficial for students' pronunciation practice in English, especially if repeated several times). The lecturer chooses a video in English with two or more characters. After the students have watched the clip and familiarized themselves with the plot, vocabulary, and grammar used, they get the printed transcript from the teacher and try to do the dubbing of the same video (played muted), i.e., do shadow reading (speaking at the same time with the characters on screen). While performing such an assignment, engineering students will be replicating key features of native speakers' connected speech, intonation, speech rate, etc. We recommend dividing the group into sub-groups, depending on the number of roles to be played.

\section{Conclusion}

The obtained positive results demonstrate the practicality of authentic video records in teaching engineers-to-be English, boosting their positive characteristics, and amending the weak points. The outcomes of the study prove our hypothesis about the effectiveness of authentic videos in improving engineering students' listening and speaking skills when such audio-visual materials are introduced in the English course regularly. Authentic videos increase students' motivation and interest in studying English, as well as their knowledge in the field of specialty, providing examples of real-life situations, 
communication, and issues. Moreover, videos in question stimulate students' critical thinking, various kinds of oral interaction, and collaboration. However, to take full advantage of videos in lessons, the foreign language lecturers should bear in mind the importance of multimedia use in diverse, compelling, and meaningful ways, always together with the variety of classroom activities (tasks), and necessarily per the technical students' specialty. In that way, the authentic video records will be considered advantageous educational aids and will bring about the desirable outcomes of the study. The conducted research creates an opportunity for further examination of authentic videos' long-term usefulness in teaching the foreign language at university and their role in each engineering student's lifelong learning of English.

\section{References}

Ardiansyah, L. D. S. (2018). Using videos in the teaching of listening. Jurnal Ilmiah Mandala Education, 4(1), 290-304. doi:10.36312/jime.v4i1.552

Babu H, R., Buddayya, R., \& Gujjarappa, N. L. (2019). Benefits of videos in YouTube for the undergraduate students in engineering and technology in India. Webology, 16(2), 57-71. doi:10.14704/web/v16i2/a190

Djebbari, Z., \& Djebbari, H. (2018). Promoting innovation and change in English education: Towards a philosophy of lifelong learning. International Journal of Linguistics, Literature and Translation (IJLLT), 1(4), 8-11. doi:10.32996/ijllt.2018.1.4.2

Eldeen, A. I. G., Abumalloh, R. A., George, R. P., \& Aldossary, D. A. (2018). Evaluation of graduate students employability from employer perspective: Review of the literature. International Journal of Engineering \& Technology, 7(2.29), 961-966. doi:10.14419/ijet.v7i2.29.14291

Elen, J., Clarebout, G., Léonard, R., \& Lowyck, J. (2007). Student-centred and teachercentred learning environments: what students think. Teaching in Higher Education, 12(1), 105-117. doi:10.1080/13562510601102339

Freitas, A., Levatino, A., \& Pécoud, A. (2012). Introduction: New perspectives on skilled migration. Diversities. Skilled Migration and the Brain Drain, 14(1), 1-7. Retrieved from http:/ / newdiversities.mmg.mpg.de/?page_id=2024

Hadijah, S. (2016). Teaching by using video: Ways to make it more meaningful in EFL classrooms. Proceedings of the Fourth International Seminar on English Language and Teaching (ISELT-4), 4(2), 307-315. Retrieved from http:// ejournal.unp.ac.id/index.php/selt/article/view/6990

Ismaili, M. (2013). The effectiveness of using movies in the EFL classroom - A study conducted at South East European University. Academic Journal of Interdisciplinary Studies, 2(4), 121-132. doi:10.5901/ajis.2012.v2n4p121

Itani, M., \& Srour, I. (2016). Engineering students' perceptions of soft skills, industry expectations, and career aspirations. Journal of Professional Issues in Engineering Education and Practice, 142(1), 04015005. doi:10.1061/(ASCE)EI.1943-5541.0000247

Kalra, R. (2017). The effectiveness of using films in the EFL classroom: A case study conducted at an International University in Thailand. Arab World English Journal, 8(3), 289-301. doi:10.24093/awej/vol8no3.19

Kline, P., \& Lapham, S. L. (1992). Personality and faculty in British universities. Personality and Individual Differences, 13(7), 855-857. doi:10.1016/01918869(92)90061-s

Malhotra, R., \& Verma, N. (2020). An impact of using multimedia presentations on engineering education. Procedia Computer Science, 172, 71-76. doi:10.1016/j.procs.2020.05.011 
Månsson, J., Löfgreen, J., \& Warfvinge, P. (2017, November 22-23). Effective use of video in engineering education. Paper presented at the 6:E Utvecklingskonferensen För Sveriges Ingenjörsutbildningar [6th Development Conference for Swedish Engineering Education], Chalmers Tekniska Högskola [Chalmers University of Technology], Göteborg, Sweden. Retrieved from https://www.lth.se/fileadmin/cee/Documents/Effective_use_of_video_in_eng ineering_education_FINAL.pdf

Markes, I. (2006). A review of literature on employability skill needs in engineering. European Journal of Engineering Education, 31(6), 637-650. doi:10.1080/03043790600911704

Muslem, A., Mustafa, F., Usman, B., \& Rahman, A. (2017). The application of video clips with small group and individual activities to improve young learners' speaking performance. Teaching English with Technology, 17(4), 25-37. Retrieved from https://www.researchgate.net/publication/320805845_The_application_of_vid eo_clips_with_small_group_and_individual_activities_to_improve_young_learn ers'_speaking_performance

Polat, M., \& Erişti, B. (2019). The effects of authentic video materials on foreign language listening skill development and listening anxiety at different levels of English proficiency. International Journal of Contemporary Educational Research, 6(1), 135154. doi:10.33200/ijcer.567863

Reddy, K. J. (2019). Relevance of listening and speaking skills for engineering students in their professional career. Language in India, 19(11), 150-159. Retrieved from http://www.languageinindia.com/nov2019/kattajanlisteningspeakingskillseng ineeringstudents.pdf

Riemer, M. J. (2003). Integrating emotional intelligence into engineering education. World Transactions on Engineering and Technology Education, 2(2), 189-194. Retrieved from

http://www.wiete.com.au/journals/WTE\&TE/Pages/Vol.2,\%20No.2\%20(2003 )/Riemer51.pdf

Saienko, N. (2017). Cognitive development of students in foreign language acquisition. Advanced education, 7, 4-8. doi:10.20535/2410-8286.77570

Saienko, N., \& Lavrysh, Y. (2020). Mobile assisted learning for self-directed learning development at technical university: SWOT analysis. Universal Journal of Educational Research, 8(4), 1466-1474. doi:10.13189/ujer.2020.080440

Shahani, S., Tahriri, A., \& Divsar, H. (2014). EFL learners' views towards video materials and viewing techniques. International SAMANM Journal of Business and Social Sciences, 2(1), 42-60. Retrieved from https://www.researchgate.net/publication/285581685_EFL_LearnersVie ws_towards_Video_Materials_and_Viewing_Techniques

Shevchenko, M. V. (2015a). Communicative approach to teaching English at technical universities. Advanced Education, 3, 101-107. doi:10.20535/2410-8286.44302

Shevchenko, M. V. (2015b). The role of authentic videos in teaching English at technical universities. Advanced Education, 4, 66-70. doi:10.20535/2410-8286.57306

Sun, L. (2020). Students' attitudes and perspectives towards using videos in technology assisted English class. Advances in Educational Technology and Psychology, 4(1), 111. doi:10.23977/aetp.2020.41001

Tordai, Z., \& Holik, I. (2018). Student's characteristics as a basis for competency development in engineering informatics education. International Journal of Engineering Pedagogy (iJEP), 8(4), 32-42. doi:10.3991/ijep.v8i4.8133

Van Der Molen, H. T., Schmidt, H. G., \& Kruisman, G. (2007). Personality characteristics of engineers. European Journal of Engineering Education, 32(5), 495-501. doi:10.1080/03043790701433111 
Wang, Z. (2015). An analysis on the use of video materials in college English teaching in China. International Journal of English Language Teaching, 2(1), 23-28. doi:10.5430/ijelt.v2n1p23

Yusoff, Y. M., Omar, M. Z., Zaharim, A., Mohamed, A., \& Muhamad, N. (2012). Formulation in evaluating the technical skills of engineering graduates. Procedia - Social and Behavioral Sciences, 60, 493-499. doi:10.1016/j.sbspro.2012.09.413

Zabalza, I., Aznar, M., Uche, J., Zalba, B., Peña, B., Marín, J. M., Llera, E. M., \& Usón, S. (2020, July). Students' feedback on the use of educational videos to support the study of Thermodynamics. EDULEARN20 Proceedings, 3832-3840. doi:10.21125/edulearn.2020.1047

Zhou, J. (2005, June). Effective use of videos to enhance the teaching and learning of Environmental Engineering. 2005 Annual Conference Proceedings. 2005 Annual Conference, Portland, Oregon. doi:10.18260/1-2--14893

\section{Appendix 1}

Pre-Experimental Questionnaire "English Studying (Engineering Specialties)"

1. Your sex:

- male

- female

2. Name of your department:

3. Which activity in English class do you find most difficult? (select no more than 2)

- listening

- reading

- writing

- speaking

4. Which task is usually the most difficult for you to do during tests in English lessons? (select no more than 2)

- listening

- reading

- writing

- speaking

5. Which task do you like to do the most in English class? (select no more than 2)

- listening

- reading

- writing

- speaking

6. Which task do you dislike to do in English class? (select no more than 2)

- listening

- reading

- writing

- speaking

7. What knowledge do you think you lack the most to be able to speak English easily? (select no more than 2)

- listening

- reading

- writing

- speaking

8. Do you like the way English is taught at the university now?

- yes

- no

9. Are you satisfied with the amount and diversity of tasks aimed to improve your communication skills in English lessons now? 
- yes

- no

10. How often do you do some further study of English at home?

- very often

- often

- rarely

- never

11. What would you change in terms of studying English at university now?

12. Does your English lecturer use videos in class to present the educational material?

- yes

- no

13. How often does your English lecturer use English-language videos in class?

- every week

- several times a month

- several times a semester

- several times a year

- videos in English are not used at all

14. Would you be interested in studying English with the help of authentic videos in English relevant to your specialty, such as fragments from movies, shows, programs?

- yes

- no

15. Would watching authentic videos in English encourage you to improve your diligence and the absence of missed (for no good reason) English lessons?

- yes

- no

\section{Appendix 2}

Post-Experimental Questionnaire of the Experimental Group “English Studying with Authentic Videos"

1. Your sex:

- male

- female

2. Name of your department:

3. Did you enjoy studying English using authentic videos?

- yes

- no

4. Were you satisfied with the amount and diversity of tasks aimed to improve your skills in English lessons with authentic videos?

- yes

- no

5. In your opinion, which skill did you improve the most while studying with the use of authentic videos? (select no more than 2)

- listening

- reading

- writing

- speaking

6. In your opinion, have you improved your knowledge of issues in the specialty field in the process of studying with authentic videos?

- yes

- no

7. After the experiment, you believe it is easier for you to recall in detail the information studied in English class 
- after reading a text

- after watching a video

8. After the experiment, can you say it has become easier for you to speak English?

- yes

- no

9. Did authentic videos used in English class help you to improve your competency? They

- helped to expand vocabulary

- helped to improve comprehension of oral speech

- helped to improve the quality of my English speaking

- helped to improve knowledge of grammar and its use

- helped to improve writing

- helped to improve reading

- helped to improve knowledge of my specialty

- helped to improve knowledge of the foreign culture

- did not help me to improve anything

10. In your opinion, after lessons with authentic videos, your English proficiency

- has increased significantly

- has increased slightly

- has not increased

11. Has your interest in studying English grown after lessons with authentic videos?

- yes

- no

12. After studying English using videos, what kind of activity in class would you prefer in the future?

- studying with the predominant use of authentic videos in English

- using only printed materials (textbook, handouts, etc.) while studying

- studying with the use of printed materials and videos (50/50)

13. Do you plan to watch authentic videos in English at home, as well, to improve your English proficiency?

- yes

- no

14. What did you like most about the English lessons with authentic videos?

15. What did you dislike about English lessons with authentic videos?

16. Do you have any recommendations for improving English lessons with authentic videos?

\section{Appendix 3}

\section{Post-Experimental Questionnaire of the Control Group "English Studying with Text Information"}

1. Your sex:

- male

- female

2. Name of your department:

3. Did you enjoy studying English using text information about engineering issues?

- yes

- no

4. Were you satisfied with the amount and diversity of tasks aimed to improve your skills in English lessons with text information?

- yes

- no 
5. In your opinion, which skill did you improve the most while studying with the use of text information? (select no more than 2)

- listening

- reading

- writing

- speaking

6. In your opinion, have you improved your knowledge of issues in the specialty field in the process of studying with the text information provided in English class?

- yes

- no

7. After the experiment, is it easy for you to recall in detail the information studied in the English class?

- yes

- no

8. After the experiment, can you say that it has become easier for you to speak English?

- yes

- no

9. Did the text information provided in the English class help you to improve your competency? It (select as many as you wish)

- helped to expand vocabulary

- helped to improve comprehension of oral speech

- helped to improve the quality of my English speaking

- helped to improve knowledge of grammar and its use

- helped to improve writing

- helped to improve reading

- helped to improve knowledge of my specialty

- helped to improve knowledge of the foreign culture

- did not help me to improve anything

10. In your opinion, after studying with the text information provided in English lessons, your English proficiency

- has increased significantly

- has increased slightly

- has not increased

11. Has your interest in studying English grown after lessons with the text information provided?

- yes

- no

12. After studying English using text information about engineering issues, what kind of activity in class would you prefer in the future?

- continue using only printed materials (textbook, handouts, etc.) while studying

- studying with the use of printed materials and videos (50/50)

- studying with the predominant use of authentic videos in English

13. Do you plan to continue studying English at home via reading text information on your specialty, similar to the one provided in class?

- yes

- no

14. What did you like most about English lessons with text information about engineering issues?

15. What did you dislike about English lessons with text information about engineering issues?

16. Do you have any recommendations for improving your English lessons? 